\title{
The von Willebrand Factor-Cleaving Protease (ADAMTS-13) and the Diagnosis of Thrombotic Thrombocytopenic Purpura (TTP)
}

\author{
Johanna A. Kremer Hovinga, Jan-Dirk Studt, Bernhard Lämmle
}

Department of Hematology and Central Hematology Laboratory, Inselspital, University of Bern, Bern, Switzerland

\section{Key Words}

Thrombotic thrombocytopenic purpura .

von Willebrand factor · von Willebrand factor-cleaving protease $\cdot$ ADAMTS-13

\begin{abstract}
Thrombotic thrombocytopenic purpura (TTP) is a lifethreatening disorder characterized by microangiopathic hemolytic anemia and thrombocytopenia as a result of microvascular platelet clumping often accompanied by ischemic organ dysfunctions such as neurological abnormalities or renal insufficiency, and fever. Until the sixties of the 20th century TTP remained an almost universally fatal disorder. The introduction of plasma exchange therapy (PE) with replacement of fresh frozen plasma has dramatically improved the survival of patients with acute TTP from less than $10 \%$ to about $80-90 \%$ and is now considered the therapy of choice. Severe deficiency of the von Willebrand factor (VWF) -cleaving protease, now denoted as ADAMTS-13, prevents normal processing of unusually large VWF multimers released from endothelial cells and it is assumed that their persistence is responsible for the formation of platelet thrombi in the microvasculature, a pathophysiological hallmark of acute TTP. An ADAMTS-13 activity of $<5 \%$ of the normal is a specific finding for acute classical TTP. However, the sensitivi-
\end{abstract}

\section{KARGER}

Fax +4161306 1234

E-Mail: karger@karger.ch www.karger.com (c) 2004 S. Karger AG, Basel 1424-8832/04/0336-0417\$21.0/0

Accessible online at: www.krager.com/pht ty of this finding for the clinical diagnosis of TTP is equivocal with reported prevalences ranging from 33 $100 \%$. Today, two forms of classical TTP are distinguished. Hereditary TTP, also known as UpshawSchulman syndrome, is caused by severe constitutional ADAMTS-13 deficiency due to compound heterozygous or homozygous mutations of the ADAMTS13 gene and patients often present with a chronic relapsing course. The acquired or sporadic form of TTP is caused by circulating autoantibodies inhibiting ADAMTS-13 activity. Relapses are also frequent in acquired TTP occurring in about $35-50 \%$ of survivors of a first bout. Despite improved treatment modalities, patients suffering from acute bouts of TTP constitute a challenge for any clinician as mortality and morbidity rates are still considerably high.

Copyright $@ 2003$ S. Karger AG, Basel

Thrombotic thrombocytopenic purpura (TTP) was first described by Moschcowitz in 1924 when he reported the case of a 16-year-old girl who died within a fortnight after abrupt onset of petechiae, anemia, micro-hematuria, fever and coma [1]. Autopsy revealed widespread "hyaline" microthrombi in the terminal arterioles and capillaries which were interpreted as agglutinated and hyalinized erythrocytes triggered by "a powerful poison which had both

\section{Dr. J. A. Kremer Hovinga,}

Central Hematology Laboratory

Inselspital, University Hospital,

CH-3010 Bern, Switzerland

Tel: +41 3163290 22; Fax: +41 3163234 06; E-mail: johanna.kremer@insel.ch 
agglutinative and hemolytic properties". Subsequent reports of similar cases led to the classic description of this syndrome by Singer et al. in 1947 [2]. TTP is characterized by microangiopathic hemolytic anemia with schistocytes on the blood smear, thrombocytopenia due to intravascular platelet clumping resulting in ischemic organ manifestations, typically neurological disturbances, renal insufficiency and fever [3]. Clinically often indistinguishable from TTP is the hemolytic uremic syndrome (HUS), which is often associated with enterohemorrhagic E. coli infection and predominantly although not exclusively diagnosed in children and elderly persons. Until the late sixties of the 20th century TTP remained an almost universally fatal disorder [4]. The empirical introduction of plasma exchange therapy with replacement of fresh frozen plasma has dramatically improved survival of patients suffering from acute TTP from $<10 \%$ [5] to about $80-90 \%$ [6,7].

During the last decade the understanding of the pathophysiology of thrombotic microangiopathies, especially TTP, has increased considerably. The first indication that von Willebrand factor (VWF) was involved in the pathogenesis of TTP came from the observation by Moake et al. [8] of unusually large VWF multimers in the plasma of patients with a chronic relapsing form of TTP. VWF is a multimeric glycoprotein composed of identical disulfidelinked $250 \mathrm{kD}$ subunits synthesized by endothelial cells and megakaryocytes and plays an important role in primary hemostasis by mediating initial platelet adhesion to the subendothelium of the damaged vessel wall at high shear rates. From the storage organelles (Weibel-Palade bodies) of endothelial cells, VWF is secreted in the form of extremely adhesive ultralarge VWF multimers into the circulation, where they are slowly but constantly attacked by plasma protease(s) and degraded into multimers ranging in size from 500 to $\sim 20$ '000kD [9]. Proteolytic cleavage occurs physiologically between the tyrosine residue at position 842 and the methionine residue at position 843 within the A2 domain of the mature VWF subunit [10]. In 1996 a specific VWF-cleaving protease was isolated from normal human plasma that cleaved purified VWF in vitro to the same fragments as those observed in vivo [11,12]. The N-terminal protein sequence of the purified VWF-cleaving protease allowed its identification as a member of the ADAMTS family of metalloproteases [13-15], named for the combination of $a$ disintegrin-like and metalloprotease with thrombospondin type 1 motifs. As the thirteenth member of this family the VWF-cleaving protease was named ADAMTS13 [15-18]. Subsequently, it was shown that most patients diagnosed with classical TTP had a severely deficient activity of this VWF-cleaving protease ( $<5 \%$ of normal) [19-22]. Today, two forms of classical TTP are distinguished. Acquired TTP is caused by circulating autoantibodies, mainly IgG, generally neutralizing ADAMTS-13 activity [21-23] while hereditary TTP (Upshaw-Schulman syndrome) is caused by severe constitutional deficiency of ADAMTS-13 [16,24-30] .

The ADAMTS-13 gene is located on chromosome 9q34, spans $\sim 37 \mathrm{~kb}$ and contains 29 exons. Congenital ADAMTS13 deficiency is the result of compound heterozygous or homozygous mutations in the ADAMTS-13 gene. The primary translation product consists of 1427 amino acid residues and consists of a signal peptide and a propeptide, followed by the motifs defining the ADAMTS family: a reprolysine-like metalloprotease domain, a disintegrin-like domain, a thrombospondin type 1 (TSP1) repeat, a characteristic cysteine-rich domain, an ADAMTS spacer domain followed by an unique combination of seven TSP1 repeats and two CUB domains (Figure 1) [15]. These various domains are conserved in other vertebrates and presumably required for ADAMTS-13 function.

Investigation into the structure-function aspects of ADAMTS-13 and into the VWF-ADAMTS-13 interaction have been initiated only recently. Using recombinant ADAMTS-13 fragments, Zheng and co-workers [31] demonstrated that constructs truncated after the metalloprotease domain, the disintegrin domain, the first TSP1 repeat or the cysteine-rich domain were devoid of any proteolytic activity towards VWF. Addition of the spacer domain restored enzymatic activity to $50 \%$, and further extension of the protein beyond the remaining seven TSP1 motifs restored activity to $80 \%$ of full-length wild type ADAMTS13. The importance of the cysteine-rich/spacer domain is further stressed by the finding that this region is consistently involved in antibody reactivity in patients with acute acquired TTP [32,33].

Several other ADAMTS-13 domains have been implicated in binding to other macromolecules, especially extracellular matrix and endothelial cells. In the circulation ADAMTS-13 docks to the surface of endothelial cells, where endothelium-anchored unusually large VWF multimers are cleaved [34,35]. Proteolytic degradation of VWF on endothelial cells is $\sim 1000$-fold enhanced compared to cleavage in the resting fluid phase [34]. Although the protein domain(s) involved in ADAMTS-13 binding to endothelial cells have not yet been identified it seems likely that the TSP1 repeats participate in this process as they may interact with a number of possible binding sites on endothelial cells, including CD36 (glycoprotein IV) or different glycosaminoglycans. In this context, it is noteworthy that anti-glycoprotein IV antibodies have been found in patients with acute TTP $[36,37]$. Binding of VWF to the endothelial cell surface is assisted by P- selectin, an adhesive protein stored in and secreted together with VWF from the Weibel-Pallade bodies upon activation of endothelial cells [38]. Protein - protein 


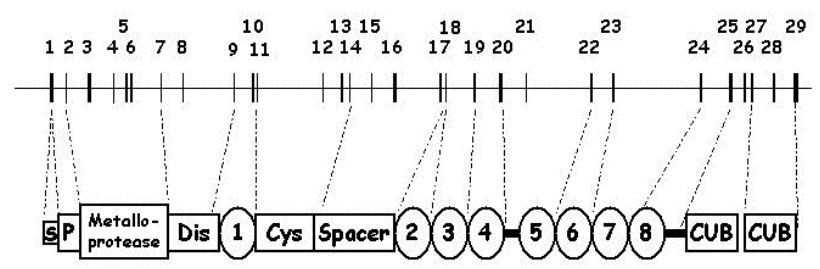

Fig. 1. Structure of the von Willebrand factor-cleaving protease, ADAMTS-13. The ADAMTS13 gene contains 29 exons in $\sim 37 \mathrm{~kb}$ on chromosome 9q34. Dashed lines show the relationship of the exons with the ADAMTS-13 protein. Proposed protein domain structure consists of a signal peptide (S), a propeptide (P), a metalloprotease, a disintegrin domain (Dis), thrombospondin type 1 repeats (numbered 1-8), a cysteine-rich domain (Cys), a spacer domain and two CUB domains (adapted from [54]).

interaction between ADAMTS-13 and VWF is mediated by the two CUB domains - unique in the ADAMTS superfamily - and adjacent thrombospondin type 1 repeats and the VWF-A3 domain [35].

Several assays have been developed for the determination of ADAMTS-13 activity in plasma. All assays consist of two principal steps: first proteolysis of VWF substrate by patient's plasma ADAMTS-13 followed by quantification of digestion products or residual VWF activity (reviewed in [39]). A multicenter study comparing several of these assays found a generally good agreement concerning the identification of severely deficient ADAMTS-13 activity, although some false-positive and one false-negative result(s) were reported by laboratories using the very delicate collagenbinding assay [40]. Figure 2 gives an example of the quantitative immunoblotting assay, applied in our laboratory $[21,41]$.

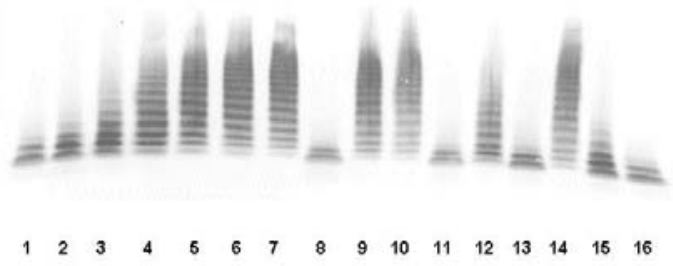

Fig. 2. Determination of ADAMTS-13 activity by immunoblotting assay [21].

Lanes 1-7: Assay calibration with dilutions of normal plasma of 1:20 (100\% activity), 1:40 (50\%), 1:80 (25\%), 1:160 (12.5\%), 1:320 (6.25\%), 1:640 (3\%), and buffer control (0\%)

Lanes 8-16: ADAMTS-13 activity determination in 1:20 dilutions of different patient plasmas displaying ADAMTS-13 activities of $\sim 100 \%$; $3 \%$; $<3 \%$; 100\%; 15\%; 100\%; <3\%; 35\% and 100\%, respectively.

von Willebrand Factor-Cleaving Protease and

Thrombotic Thrombocytopenic Purpura
The discovery of two brothers with chronic relapsing TTP and the linkage of their disease to the complete deficiency of ADAMTS-13 activity at the Hemostasis Research Laboratory, Inselspital, University of Bern [19] and the subsequent identification of the underlying ADAMTS13 mutations [26] prompted many clinicians to refer plasma and whole blood samples of similar cases. As of May 2004 we have identified 38 patients with a severe constitutional ADAMTS-13 deficiency from 29 families in 13 countries (worldwide about 60 families). Analysis of patient histories revealed a striking age-dependent clustering of the first TTP attack. Half of the patients suffered from their first acute bout of TTP between the first day of life and the age of about five years (early onset), while the other half remained asymptomatic into early adulthood and suffered from a first acute TTP episode at the age of 20-40 years (late onset) [42]. In most of the families with two or more affected siblings the age at initial disease manifestation was comparable. Six female patients from four families had their first attack during a first pregnancy.

Today, over 70 different ADAMTS-13 mutations have been reported of which 2 thirds are missense mutations [16,24-30]. In addition, several single nucleotide polymorphisms (SNPs) have been identified. These mutations and SNPs are not restricted to a specific domain but distributed throughout the whole protein. So far, about one third of the reported missense and nonsense mutations have been expressed and were not or merely marginally secreted $[24,29,43]$. Despite the apparent familial clustering of age at disease onset there is no link between the clinical phenotype and the underlying genotype. Besides severe ADAMTS-13 deficiency apparently additional, hitherto unidentified triggers are necessary for the onset of an acute TTP episode, at least in some patients. This is supported by the observation of two unrelated males with severe ADAMTS-13 deficiency who remained asymptomatic into their fourth and fifth decades of life although both had affected sisters [42]. However, regardless of the age at disease onset, once affected individuals developed a first bout of TTP they usually had a chronic relapsing course [42].

Hereditary TTP is considered an extremely rare disorder, however, our own observations and those of others [25] suggest, that the prevalence of Upshaw-Schulman syndrome may have been greatly underestimated: Several siblings of patients diagnosed in our laboratory had died without established diagnosis, a substantial proportion had been diagnosed as Evans' syndrome or ITP resulting in inefficacious immunosuppressive treatment, and in others diagnosis was greatly delayed and made only after irreversible organ damage, such as ischemic neurologic deficits or permanent renal insufficiency had occurred, or even postmortem [44]. Patients with Upshaw-Schulman syndrome respond dramat-

Pathophysiol Haemost Thromb 2003/2004;33:417-421 
ically to simple FFP infusion [42,44-48] and can be maintained for many years in good health by regular FFP infusion every 2-3 weeks $[42,44,48]$.

Although severe deficiency of ADAMTS-13 activity ( $<5 \%$ of normal) is a specific finding for acute idiopathic TTP, the sensitivity of this finding for the clinical diagnosis of idiopathic TTP remains equivocal. In several retrospective studies clinically diagnosed acute TTP was associated with severe ADAMTS-13 deficiency in $52-100 \%$ of patients [21,22,49-51]. A similar prevalence of severe ADAMTS-13 deficiency of $71 \%$ was found in a prospective study [52], while a considerably lower prevalence of only 33\% (16/48 patients) was reported recently in an inception cohort study of 142 consecutive adult patients [53]. In this latter study patients were diagnosed as having acute idiopathic TTPHUS on the basis of thrombocytopenia and microangiopathic hemolytic anemia without another apparent etiology without distinction between TTP or HUS. Apparently other, hitherto unidentified pathogenetic factors may lead to a condition clinically indistinguishable from that seen in severe
ADAMTS-13 deficiency [3,42]. Therefore, TTP with severe ADAMTS-13 deficiency and TTP without severe ADAMTS-13 deficiency may well represent two distinct disease entities. This seems to be supported by the notion of a considerably higher mortality in patients suffering from acute TTP without (67\%) compared to that in those with severe ADAMTS-13 deficiency (17\%) despite appropriate treatment regimens [49], suggesting that plasma exchange might not be the optimal treatment for the former patients. This is refuted, however, by the Oklahoma TTP-HUS registry [53], where TTP-HUS related mortality, defined as mortality within the first 30 days of completion of plasma therapy, was similar in patients suffering from acute idiopathic TTP-HUS irrespective of the presence or absence of severe ADAMTS-13 deficiency. Therefore, plasma exchange therapy with replacement of fresh frozen plasma remains mandatory for all patients presenting with an acute bout of TTP regardless of their ADAMTS-13 activity.

\section{References}

1 Moschcowitz E. Hyaline thrombosis of the terminal arterioles and capillaries: a hitherto undescribed disease. Proc N Y Pathol Soc 1924;24:2124.

2 Singer K, Bornstein F, Wiles A. Thrombotic thrombocytopenic purpura. Blood 1947;2:542-544

3. Moake JL. Thrombotic microangiopathies. N Engl J Med 2002;347:589-600.

4 Shepard KV, Bukowski RM. The treatment of thrombotic thrombocytopenic purpura with exchange transfusions, plasma infusions, and plasma exchange. Semin Hemato. 1987;24:178-193.

5 Amorosi EL, Ultmann JE. Thrombotic thrombocytopenic purpura: report of 16 cases and review of the literature. Medicine (Baltimore) 1966;45:139-159.

6 Rock GA, Shumak KH, Buskard NA, Blanchette VS, Kelton JG, Nair RC, Spasoff RA. Comparison of plasma exchange with plasma infusion in the treatment of thrombotic thrombocytopenic purpura. Canadian Apheresis Study Group. N Engl J Med 1991;325:393-397.

7 Bell WR, Braine HG, Ness PM, Kickler TS. Improved survival in thrombotic thrombocytopenic purpura-hemolytic uremic syndrome. Clinical experience in 108 patients. N Engl J Med 1991;325:398-403.

8 Moake JL, Rudy CK, Troll JH, Weinstein MJ, Colannino NM, Azocar J, Seder RH, Hong SL, Deykin D. Unusually large plasma factor VIII:von Willebrand factor multimers in chronic relapsing thrombotic thrombocytopenic purpura. N Engl J Med 1982;307:1432-1435

$\checkmark$ Sadler JE. Biochemistry and genetics of von Willebrand factor. Annu Rev Biochem 1998;67:395-424.
10 Dent JA, Berkowitz SD, Ware J, Kasper CK, Ruggeri ZM. Identification of a cleavage site directing the immunochemical detection of molecular abnormalities in type IIA von Willebrand factor. Proc Natl Acad Sci USA 1990;87:6306-6310

11 Furlan M, Robles R, Lämmle B. Partial purification and characterization of a protease from human plasma cleaving von Willebrand factor to fragments produced by in vivo proteolysis. Blood 1996;87:4223-4234

12 Tsai HM. Physiologic cleavage of von Willebrand factor by a plasma protease is dependent on its conformation and requires calcium ion. Blood 1996;87:4235-4244.

13 Fujikawa K, Suzuki H, McMullen B, Chung D. Purification of human von Willebrand factorcleaving protease and its identification as a new member of the metalloproteinase family. Blood 2001;98:1662-1666.

14 Gerritsen HE, Robles R, Lämmle B, Furlan M. Partial amino acid sequence of purified von Willebrand factor-cleaving protease. Blood 2001;98:1654-1661.

15 Zheng X, Chung D, Takayama TK, Majerus EM, Sadler JE, Fujikawa K. Structure of von Willebrand factor-cleaving protease (ADAMTS13), a metalloprotease involved in thrombotic thrombocytopenic purpura. J Biol Chem 2001; 276:41059-41063.

16 Levy GG, Nichols WC, Lian EC, Foroud T, McClintick JN, McGee BM, Yang AY, Siemieniak DR, Stark KR, Gruppo R, Sarode R, Shurin SB, Chandrasekaran V, Stabler SP, Sabio $\mathrm{H}$, Bouhassira EE, Upshaw JD, Jr., Ginsburg D, Tsai HM. Mutations in a member of the ADAMTS gene family cause thrombotic thrombocytopenic purpura. Nature 2001;413:488-494.
17 Soejima K, Mimura N, Hirashima M, Maeda H, Hamamoto T, Nakagaki T, Nozaki C. A novel human metalloprotease synthesized in the liver and secreted into the blood: possibly, the von Willebrand factor-cleaving protease? J Biochem (Tokyo) 2001;130:475-480

18 Plaimauer B, Zimmermann K, Volkel D, Antoine G, Kerschbaumer R, Jenab P, Furlan M, Gerritsen H, Lämmle B, Schwarz HP, Scheiflinger F. Cloning, expression, and functional characterization of the von Willebrand factor-cleaving protease (ADAMTS13). Blood 2002;100:3626-3632.

19 Furlan M, Robles R, Solenthaler M, Wassmer M, Sandoz P, Lämmle B. Deficient activity of von Willebrand factor-cleaving protease in chronic relapsing thrombotic thrombocytopenic purpura. Blood 1997;89:3097-3103.

20 Furlan M, Lämmle B. Deficiency of von Willebrand factor-cleaving protease in familial and acquired thrombotic thrombocytopenic purpura. Baillieres Clin Haematol 1998;11:509-514.

21 Furlan M, Robles R, Galbusera M, Remuzzi G Kyrle PA, Brenner B, Krause M, Scharrer I, Aumann V, Mittler U, Solenthaler M, Lämmle B. Von Willebrand factor-cleaving protease in thrombotic thrombocytopenic purpura and the hemolytic-uremic syndrome. N Engl J Med 1998;339: 1578-1584.

22 Tsai HM, Lian EC. Antibodies to von Willebrand factor-cleaving protease in acute thrombotic thrombocytopenic purpura. N Engl J Med 1998;339:1585-1594.

23 Furlan M, Robles R, Solenthaler M, Lämmle B. Acquired deficiency of von Willebrand factorcleaving protease in a patient with thrombotic thrombocytopenic purpura. Blood 1998;91:28392846. 
24 Kokame K, Matsumoto M, Soejima K, Yagi H, Ishizashi $\mathrm{H}$, Funato $\mathrm{M}$, Tamai $\mathrm{H}$, Konno $\mathrm{M}$, Kamide K, Kawano Y, Miyata T, Fujimura Y. Mutations and common polymorphisms in ADAMTS13 gene responsible for von Willebrand factor-cleaving protease activity. Proc Natl Acad Sci USA 2002;99:11902-11907.

25 Schneppenheim R, Budde U, Oyen F, Angerhaus D, Aumann V, Drewke E, Hassenpflug W, Häberle J, Kentouche K, Kohne E, Kurnik K, MuellerWiefel D, Obser T, Santer R, Sykora KW. Von Willebrand factor cleaving protease and ADAMTS13 mutations in childhood TTP. Blood 2003;101:1845-1850.

26 Antoine G, Zimmermann K, Plaimauer B, Grillowitzer M, Studt JD, Lämmle B, Scheiflinger F. ADAMTS13 gene defects in two brothers with constitutional thrombotic thrombocytopenic purpura and normalization of von Willebrand factorcleaving protease activity by recombinant human ADAMTS13. Br J Haematol 2003;120:821-824.

27 Savasan S, Lee SK, Ginsburg D, Tsai HM. ADAMTS13 gene mutation in congenital thrombotic thrombocytopenic purpura with previously reported normal VWF cleaving protease activity. Blood 2003;101:4449-4451.

28 Assink K, Schiphorst R, Allford S, Karpman D, Etzioni A, Brichard B, van de Kar N, Monnens L, van den Heuvel L. Mutation analysis and clinical implications of von Willebrand factor-cleaving protease deficiency. Kidney Int 2003;63:19951999.

29 Matsumoto M, Kokame K, Soejima K, Miura M, Hayashi S, Fujii Y, Iwai A, Ito E, Tsuji Y, TakedaShitaka M, Iwadate M, Umeyama $\mathrm{H}$, Yagi $\mathrm{H}$, Ishizashi H, Banno F, Nakagaki T, Miyata T, Fujimura Y. Molecular characterization of ADAMTS13 gene mutations in Japanese patients with Upshaw-Schulman syndrome. Blood 2004;103:1305-1310.

30 Veyradier A, Lavergne JM, Ribba AS, Obert B, Loirat C, Meyer D, Girma JP. Ten candidate ADAMTS13 mutations in six French families with congenital thrombotic thrombocytopenic purpura (Upshaw-Schulman syndrome). J Thromb Haemost 2004;2:424-429.

31 Zheng X, Nishio K, Majerus EM, Sadler JE. Cleavage of von Willebrand factor requires the spacer domain of the metalloprotease ADAMTS13. J Biol Chem 2003;278:30136-30141.

32 Soejima K, Matsumoto M, Kokame K, Yagi H, Ishizashi H, Maeda H, Nozaki C, Miyata T, Fujimura Y, Nakagaki T. ADAMTS-13 cysteinerich/spacer domains are functionally essential for von Willebrand factor cleavage. Blood 2003;102:3232-3237.
33 Klaus C, Plaimauer B, Studt JD, Dorner F, Lämmle B, Mannucci PM, Scheiflinger F. Epitope mapping of ADAMTS13 autoantibodies in acquired thrombotic thrombocytopenic purpura. Blood 2004;103:4514-4519.

34 Dong JF, Moake JL, Nolasco L, Bernardo A, Arceneaux W, Shrimpton CN, Schade AJ, McIntire LV, Fujikawa K, Lopez JA. ADAMTS13 rapidly cleaves newly secreted ultralarge von Willebrand factor multimers on the endothelial surface under flowing conditions. Blood 2002;100:4033-4039.

35 Dong JF, Moake JL, Bernardo A, Fujikawa K, Ball C, Nolasco L, Lopez JA, Cruz MA. ADAMTS-13 metalloprotease interacts with the endothelial cellderived ultra-large von Willebrand factor. J Biol Chem 2003;278:29633-29639.

36 Tandon NN, Rock G, Jamieson GA. Anti-CD36 antibodies in thrombotic thrombocytopenic purpura. Br J Haematol 1994;88:816-825.

37 Schultz DR, Arnold PI, Jy W, Valant PA, Gruber J, Ahn YS, Mao FW, Mao WW, Horstman LL. AntiCD36 autoantibodies in thrombotic thrombocytopenic purpura and other thrombotic disorders: identification of an $85 \mathrm{kD}$ form of CD36 as a target antigen. Br J Haematol 1998;103:849-857.

38 Padilla A, Moake JL, Bernardo A, Ball C, Wang Y, Arya M, Nolasco L, Turner N, Berndt MC, Anvari B, Lopez JA, Dong JF. P-selectin anchors newly released ultralarge von Willebrand factor multimers to the endothelial cell surface. Blood 2004; 103:2150-2156

39 Veyradier A, Girma JP. Assays of ADAMTS-13 activity. Semin Hematol 2004;41:41-47.

40 Studt JD, Böhm M, Budde U, Girma JP, Varadi K, Lämmle B. Measurement of von Willebrand factor-cleaving protease (ADAMTS-13) activity in plasma: a multicenter comparison of different assay methods. J Thromb Haemost 2003;1:18821887.

41 Bianchi V, Robles R, Alberio L, Furlan M, Lämmle B. Von Willebrand factor-cleaving protease (ADAMTS13) in thrombocytopenic disorders: a severely deficient activity is specific for thrombotic thrombocytopenic purpura. Blood 2002;100:710-713.

42 Furlan M, Lämmle B. Aetiology and pathogenesis of thrombotic thrombocytopenic purpura and haemolytic uraemic syndrome: the role of von Willebrand factor-cleaving protease. Best Pract Res Clin Haematol 2001;14:437-454.

43 Schneppenheim R, Budde U, Hassenpflug W, Obser T. Severe ADAMTS-13 deficiency in childhood. Semin Hematol 2004;41:83-89.
44 Studt JD, Kremer Hovinga JA, Alberio L, Bianchi V, Lämmle B. Von Willebrand factor-cleaving protease (ADAMTS-13) activity in thrombotic microangiopathies: diagnostic experience 2001/2002 of a single research laboratory. Swiss Med Wkly 2003;133:325-332.

45 Upshaw JD. Congenital deficiency of a factor in normal plasma that reverses microangiopathic hemolysis and thrombocytopenia. N Engl J Med 1978;298:1350-1352.

46 Allford SL, Harrison P, Lawrie AS, Liesner R, MacKie IJ, Machin SJ. Von Willebrand factorcleaving protease activity in congenital thrombotic thrombocytopenic purpura. $\mathrm{Br} \mathrm{J}$ Haematol 2000;111:1215-1222.

47 Kinoshita S, Yoshioka A, Park YD, Ishizashi $\mathrm{H}$ Konno M, Funato M, Matsui T, Titani K, Yagi H, Matsumoto M, Fujimura Y. Upshaw-Schulman syndrome revisited: a concept of congenital thrombotic thrombocytopenic purpura. Int J Hematol 2001;74:101-108

48 Barbot J, Costa E, Guerra M, Barreirinho MS, Isvarlal P, Robles R, Gerritsen HE, Lämmle B, Furlan M. Ten years of prophylactic treatment with fresh-frozen plasma in a child with chronic relapsing thrombotic thrombocytopenic purpura as a result of a congenital deficiency of von Willebrand factor-cleaving protease. $\mathrm{Br} \mathrm{J}$ Haematol 2001;113:649-651.

49 Mori Y, Wada H, Gabazza EC, Minami N, Nobori T, Shiku H, Yagi H, Ishizashi H, Matsumoto M, Fujimura Y. Predicting response to plasma exchange in patients with thrombotic thrombocytopenic purpura with measurement of vWF-cleaving protease activity. Transfusion 2002;42:572 580.

50 Kremer Hovinga JA, Studt JD, Alberio L, Lämmle B. von Willebrand factor-cleaving protease (ADAMTS-13) activity determination in the diagnosis of thrombotic microangiopathies: the Swiss experience. Semin Hematol 2004;41:75-82.

1 Matsumoto M, Yagi $H$, Ishizashi $H$, Wada $H$ Fujimura Y. The Japanese experience with thrombotic thrombocytopenic purpura-hemolytic uremic syndrome. Semin Hematol 2004:41:68-74.

52 Veyradier A, Obert B, Houllier A, Meyer D, Girma JP. Specific von Willebrand factor-cleaving protease in thrombotic microangiopathies: a study of 111 cases. Blood 2001;98:1765-1772.

53 Vesely SK, George JN, Lämmle B, Studt JD, Alberio L, El-Harake MA, Raskob GE. ADAMTS13 activity in thrombotic thrombocytopenic purpura-hemolytic uremic syndrome: relation to presenting features and clinical outcomes in a prospective cohort of 142 patients. Blood 2003;102:60-68.

54 Zheng X, Majerus EM, Sadler JE. ADAMTS13 and TTP. Curr Opin Hematol 2002;9:389-394. 